\title{
Research on the Power Recovery of Diesel Engines with Regulated Two-Stage Turbocharging System at Different Altitudes
}

\author{
Hualei Li, Lei Shi, and Kangyao Deng \\ Key Laboratory for Power Machinery and Engineering of Ministry of Education, Shanghai Jiao Tong University, \\ Shanghai 200240, China
}

Correspondence should be addressed to Kangyao Deng; kydeng@sjtu.edu.cn

Received 29 November 2013; Accepted 20 January 2014; Published 26 March 2014

Academic Editor: Zuohua Huang

Copyright (C) 2014 Hualei Li et al. This is an open access article distributed under the Creative Commons Attribution License, which permits unrestricted use, distribution, and reproduction in any medium, provided the original work is properly cited.

\begin{abstract}
Recovering the boost pressure is very important in improving the dynamic performance of diesel engines at high altitudes. A regulated two-stage turbocharging system is an adequate solution for power recovery of diesel engines. In the present study, the change of boost pressure and engine power at different altitudes was investigated, and a regulated two-stage turbocharging system was constructed with an original turbocharger and a matched low pressure turbocharger. The valve control strategies for boost pressure recovery, which formed the basis of the power recovery method, are presented here. The simulation results showed that this system was effective in recovering the boost pressure at different speeds and various altitudes. The turbine bypass valve and compressor bypass valve had different modes to adapt to changes in operating conditions. The boost pressure recovery could not ensure power recovery over the entire operating range of the diesel engine, because of variation in overall turbocharger efficiency. The fuel-injection compensation method along with the valve control strategies for boost pressure recovery was able to reach the power recovery target.
\end{abstract}

\section{Introduction}

Diesel engines are widely used in the fields of industry, agriculture, and transportation. Diesel engines equipped with turbochargers can experience improvements in power density and emission behavior. However, turbocharging systems are typically matched to diesel engines based on the performance of diesel engines operating at sea level or fixed altitudes. Some important problems arise when diesel engines are required to operate at high altitude or varying altitudes.

Ambient pressure and temperature decrease with the increase of altitude. The turbine back pressure and turbine power increase for turbocharged diesel engines, and the pressure ratio and speed of the compressor increase. This phenomenon is called the "self-compensation ability" of a turbocharger. However, the pressure ratio increase cannot compensate for the decrease of ambient pressure and the boost pressure and the mass flow rate of intake air into the cylinder decrease. Therefore, the air fuel ratio of the diesel engine is reduced, resulting in lower engine power and higher exhaust temperature. The dynamic performance and thermal load of a diesel engine deteriorates with increased altitudes, while the brake-specific fuel consumption increases $[1,2]$.

Traditional single-stage turbocharging systems cannot meet the high pressure ratio and wide flow range requirements for different altitudes due to the inherent characteristics of rotary machines [3-5]. A regulated two-stage (RTS) turbocharging system can be used to compensate for the decrease in boost pressure and reduction in power of a diesel engine operating at high altitude.

The regulated two-stage turbocharging system achieves a significant pressure ratio increase and a wider operating flow range due to its greater flexibility [6-9]. There are several papers published on the regulated two-stage turbocharging system for different altitudes. Simulations of onestage and two-stage turbocharged diesel engines operating at different altitudes showed that the maximum torque and rated power increased with a two-stage turbocharging system [10]. In another study, a well-matched, two-stage sequential 
TABLE 1: Specifications of the D6114 diesel engine.

\begin{tabular}{lc}
\hline Type & $\begin{array}{c}\text { Cylinder inline, 6-cylinder, } 4 \text { stroke } \\
\text { turbocharged and intercooled }\end{array}$ \\
Turbocharging system & $8.26 \mathrm{~L}$ \\
Displacement & $114 \mathrm{~mm}$ \\
Bore & $135 \mathrm{~mm}$ \\
Stroke & 17.7 \\
Compression ratio & $184 \mathrm{~kW}$ \\
Rated power & $2200 \mathrm{r} / \mathrm{min}$ \\
Rated speed & $1400 \mathrm{r} / \mathrm{min}$ \\
Maximum torque speed & Garrett TBP4 \\
Turbocharger &
\end{tabular}

turbocharging system was proposed to meet the power output requirements at different altitudes [11]. A two-stage turbocharging system was matched for a light aeroengine operating at high altitude, and the results showed that a matched two-stage turbocharging system met the engine and design requirements [12]. The investigators performed a simulation of a two-stage turbocharging system and demonstrated the effectiveness of the two-stage turbocharging system for various altitudes. However, valve control strategies for recovering the boost pressure and the method for power recovery at different altitudes have not been considered or researched in detail. In the previous research, the switching boundaries of the bypass valves were not investigated and determined. But the switching boundaries were also very important for the regulated two-stage turbocharging system. So the power recovery of diesel engines was discussed definitely with regulated two-stage turbocharging system at different altitudes in this paper, and the switching boundaries of the bypass valves were also specified according to different speeds and various altitudes.

In this paper, the effects of altitude on intake pressure and engine power were simulated at different speeds and various altitudes. A regulated two-stage turbocharging system was matched, and the performance of diesel engine was recovered. Valve control strategies for boost pressure recovery at different altitudes were examined with the simulation method, and the method for power recovery was tested.

\section{Simulation Setup and Verification}

A six-cylinder inline D6114 diesel engine with 8.26 liters displacement was selected for the study. The main features are listed in Table 1. Simulations were carried out on GT-Power software, a one-dimensional fluid-dynamic code developed by Gamma Technologies for engine performance prediction. The model required a detailed schematization of the engine and of the intake and exhaust system geometry. The heat release profiles obtained from experimental in-cylinder pressure traces were used for the simulation. The turbine and compressor models were modeled by performance maps.

The computed and experimental results were compared and the relative errors of the model at rated speed and maximum torque speed are shown in Figures 1 and 2, respectively. The computed and experimental results agree with each

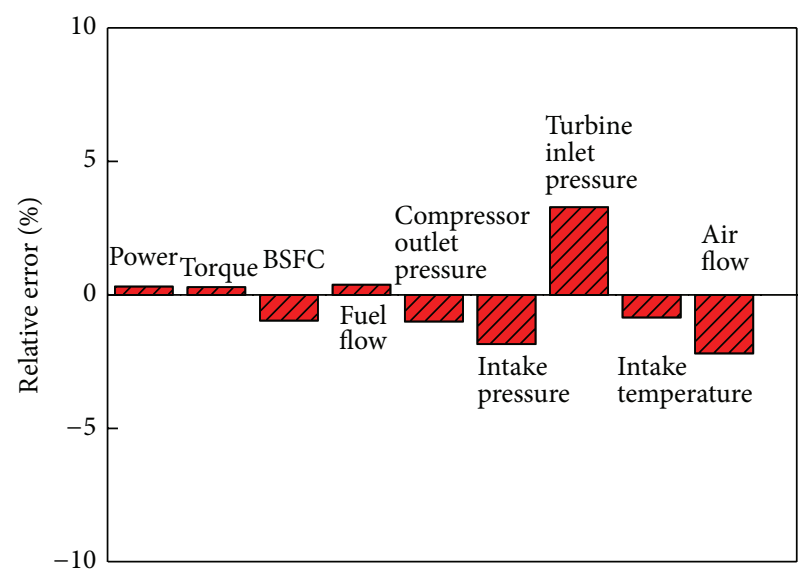

FIGURE 1: Relative errors of the simulation model at the rated speed.

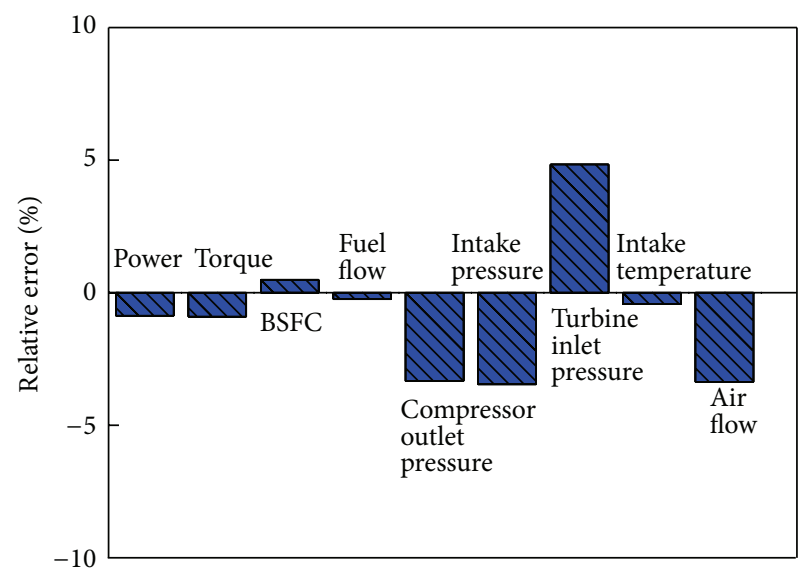

FIGURE 2: Relative errors of the simulation model at the maximum torque speed.

other, with differences being within $+/-5 \%$. Therefore, the simulation model of the original engine was deemed suitable for predicting engine performance.

\section{Performance Analysis of the Baseline Engine at Various Altitudes}

After the model was validated, the effects of altitude on engine performance were simulated. The pressure and temperature in the environment module were changed to represent different altitudes according to Figure 3. Ambient pressure and ambient temperature decrease linearly with the increase of altitude.

The effect of altitude on intake pressure at different engine speeds is presented in Figure 4. The extent of intake pressure reduction caused by an increase in altitude was dependent on the engine speed. The intake pressure at $1400 \mathrm{r} / \mathrm{min}$ decreased from $200 \mathrm{kPa}$ to $147 \mathrm{kPa}$ when the ambient pressure changed from $100 \mathrm{kPa}$ to $70 \mathrm{kPa}$. However, the intake pressure at $1700 \mathrm{r} / \mathrm{min}$ remained constant with a change in ambient pressure. The intake pressure decreased quickly at lower engine speeds. This could be explained by the control of 


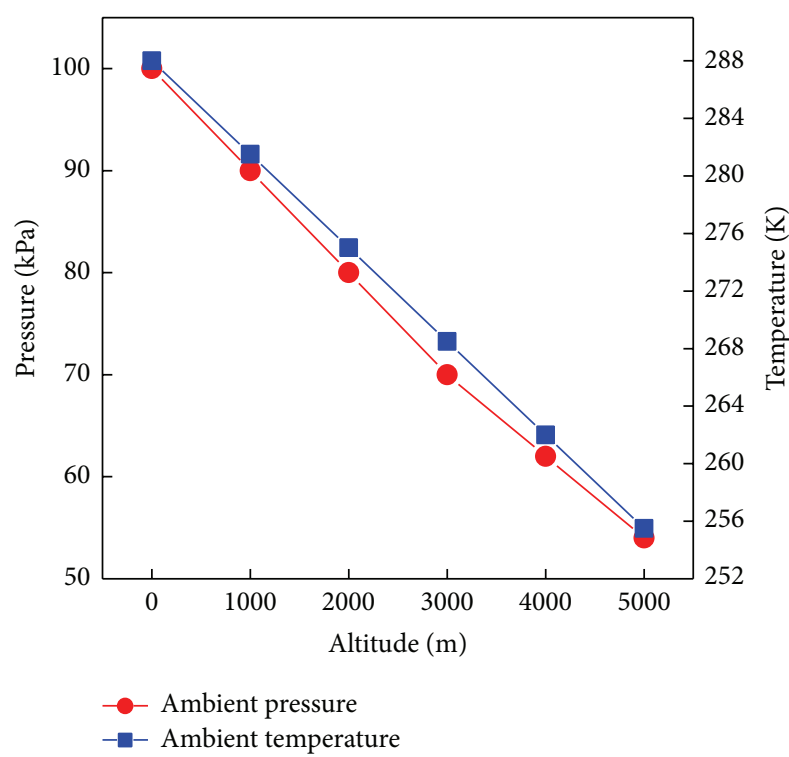

Figure 3: Ambient pressure and temperature at different altitudes.

the waste-gate valve and the self-compensation ability of the turbocharger.

The matching point between the baseline engine and the TBP4 turbocharger was the maximum torque speed. The waste-gate valve was placed to avoid the overspeed of the turbocharger and was controlled based on the intake pressure. The opening degree of waste-gate valve at different speeds was reduced to regulate the intake pressure with the increased altitudes.

The increased altitude resulted in the decrease of turbine outlet pressure. The turbine expansion ratio and turbine power were increased to compensate for the effect of increased altitude. Therefore, the compressor pressure ratio and intake pressure were improved. The extent of the self-compensation ability differed at different engine speeds. Operation at high engine speeds resulted in higher exhaust energy and thus better self-compensation ability.

The decrease of intake pressure resulted in the decrease of the mass flow rate of fresh air, decreasing the dynamic performance of the engine. The results (Figure 5) show that the rate of reduction of engine power was dependent on engine speed. The rate of reduction was $10 \%$ per $1000 \mathrm{~m}$ at $1400 \mathrm{r} / \mathrm{min}$ but was much lower at a higher speed $(1700 \mathrm{r} / \mathrm{min})$.

\section{Steady-State Matching and Valve Control Strategy}

With the turbocharger's self-compensation ability, the performance of a diesel engine with a single-stage turbocharging system can be improved at different altitudes. However, the boost pressure and engine power of diesel engine still decreased with the increase of altitude. The single-stage turbocharging system was not adequate to compensate for the decrease of boost pressure and engine power at high altitudes. Therefore, the regulated two-stage turbocharging system was

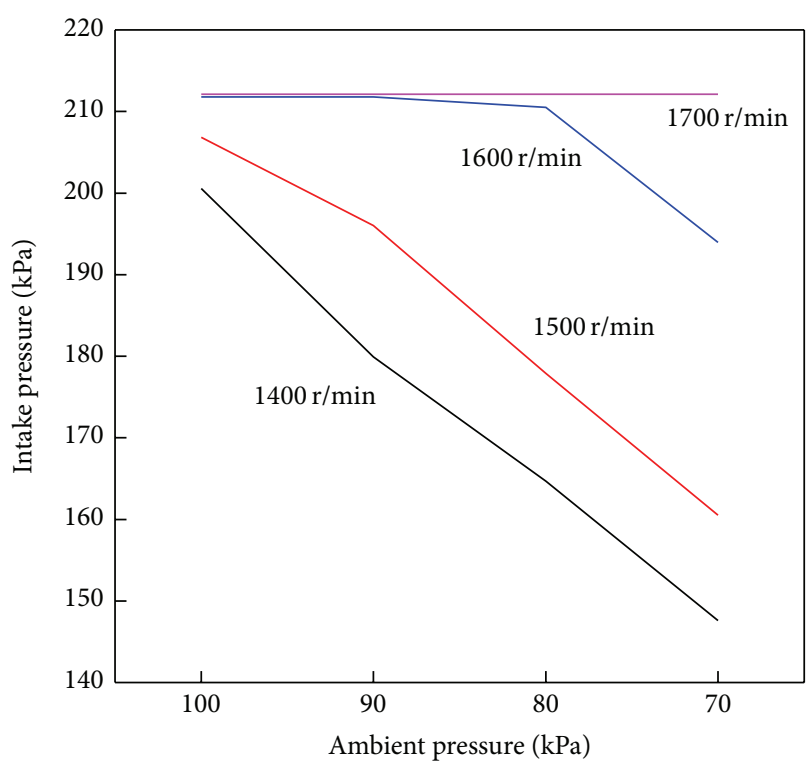

FIGURE 4: Effect of altitude on the intake pressure for different engine speeds.

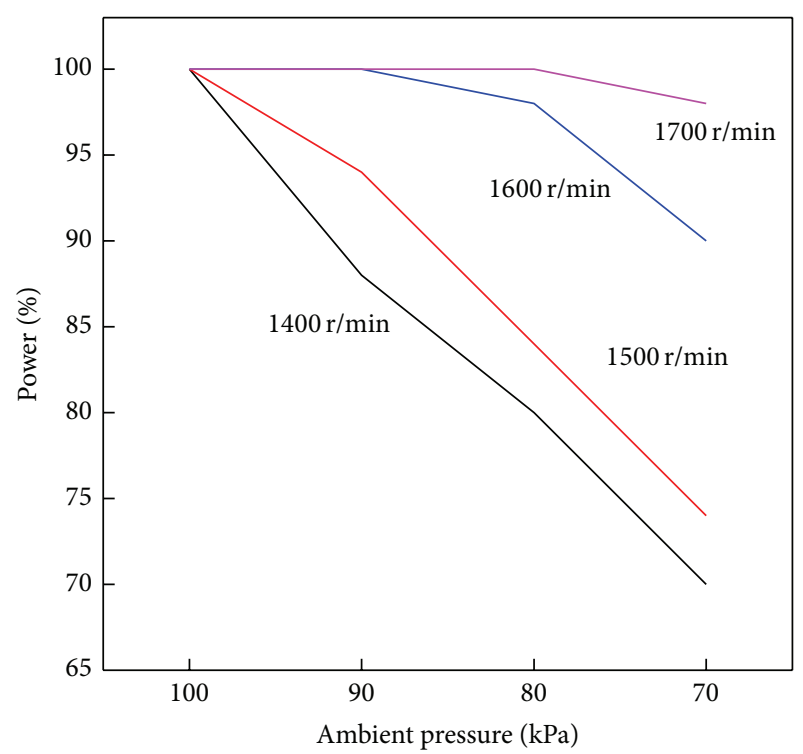

FIGURE 5: Effect of altitude on the engine power for different engine speeds.

employed to compensate for the decrease in boost pressure and engine power.

The RTS turbocharging system configuration for recovering the boost pressure consisted of two turbochargers in series. The original TBP4 turbocharger was used as the high pressure stage, and the waste-gate valve was removed. The objective of steady-state matching was to determine a bigger and suitable turbocharger for the low pressure stage.

The maximum torque speed and full load at an altitude of $3000 \mathrm{~m}$ was considered the matching point of the turbocharging system. 


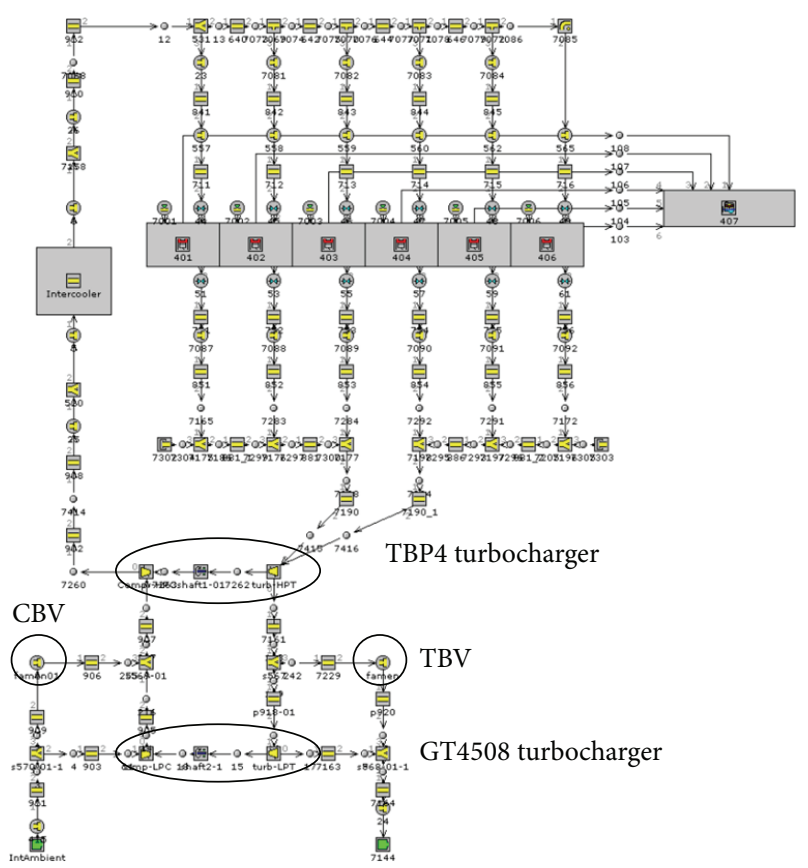

FIGURE 6: Schematic diagram of the RTS system for boost pressure recovery.

Careful matching of the low pressure turbocharger is important to achieve optimum engine performance. The maximum torque speed and full load at an altitude of $3000 \mathrm{~m}$ were considered the matching point of the turbocharging system. Additionally, the turbine flow area of the low pressure turbocharger needed to provide a high enough pressure ratio at the matching point when used in conjunction with the TBP4 turbocharger. The compressor flow area of the low pressure turbocharger also needed to meet the requirements at both the rated speed and full load at $3000 \mathrm{~m}$. The low pressure turbocharger adopted (GT4508 turbocharger provided by the Honeywell Company) was selected according to the above requirements.

Once the low pressure turbocharger was selected, the model was modified to a two-stage turbocharged engine, shown in Figure 6. A turbine bypass valve (TBV) was placed across the turbine of the GT4508 turbocharger, and a compressor bypass valve (CBV) was placed across the compressor. The model was then used to estimate engine performance attained by means of the RTS system.

A bypass flow rate ratio is defined as the ratio of the mass flow rate of the TBV to the total mass flow rate of exhaust gas. The RTS system bypassed the exhaust gas of the low pressure turbine into the TBV. Therefore, the bypass flow rate ratio represents the opening degree of the TBV. The TBV control is primarily undertaken by the TBV that keeps the desired full load boost pressure.

The full load boost pressure of the maximum torque speed reached the target values at various altitudes with the matched RTS system (Figure 7). The opening degree of the TBV was increased with the increase of ambient pressure. When the ambient pressure was $70 \mathrm{kPa}$, the bypass flow rate

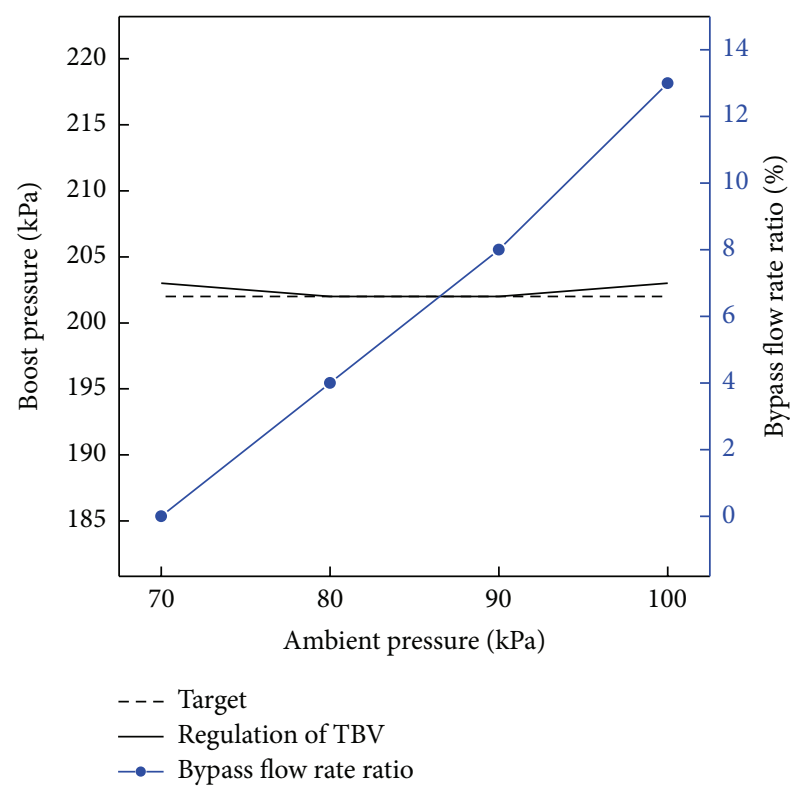

FIGURE 7: Control of the full load boost pressure at various altitudes.

ratio was zero. The TBV was closed to maintain a small turbine equivalent area to maximize the pressure ratio of the turbocharging system. When the ambient pressure increased, the RTS system was not required to provide such a high pressure ratio. Therefore, the TBV was gradually opened to maintain the target boost pressure value.

Pressure ratios of the two-stage turbochargers at various altitudes are shown in Figure 8. The TBV control affected the pressure ratio of the low pressure stage due to the reduced ambient pressure. The regulating effect of the TBV control on the pressure ratio of the high pressure stage was not significant, resulting in little change in the pressure ratio of the high pressure stage at various altitudes. Therefore, the resultant total pressure ratio provided by the RTS system increased with increased altitude. The pressure ratio of the high pressure stage was much higher than that of the low pressure stage. This shows that the high pressure turbocharger played a primary role in compressing the intake air. The low pressure turbocharger operated just to assist the compression work.

The full load boost pressure reached the values for different speeds at $3000 \mathrm{~m}$ (Figure 9). The opening degree of the TBV increased with increasing engine speed. The bypass flow rate ratio was zero at the maximum torque speed $(1400 \mathrm{r} / \mathrm{min})$. When the engine speed increased, the TBV was gradually opened to maintain the boost pressure at the target value.

Pressure ratios of the two-stage turbocharger for different speeds at $3000 \mathrm{~m}$ are shown in Figure 10. The TBV control at different speeds regulated the exhaust energy between the high pressure turbine and the low pressure turbine and affected the pressure ratio distribution. The pressure ratio of the high pressure stage increased gradually with the increase in engine speed, and the pressure ratio of the low pressure stage decreased correspondingly. Therefore, the resultant 


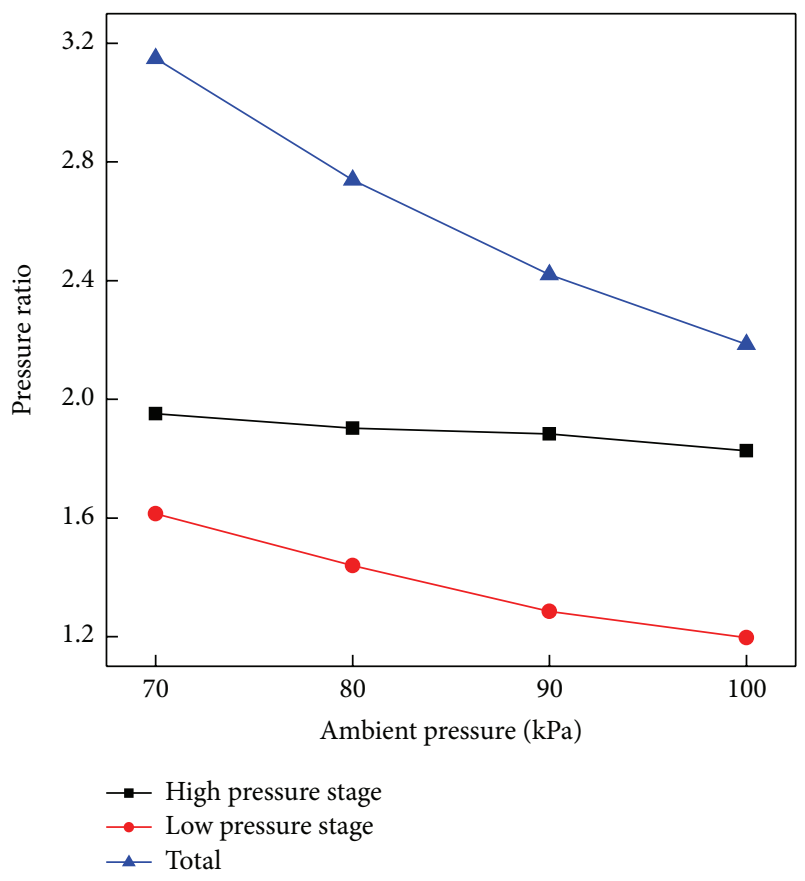

Figure 8: Pressure ratios of the two-stage turbochargers at various altitudes.

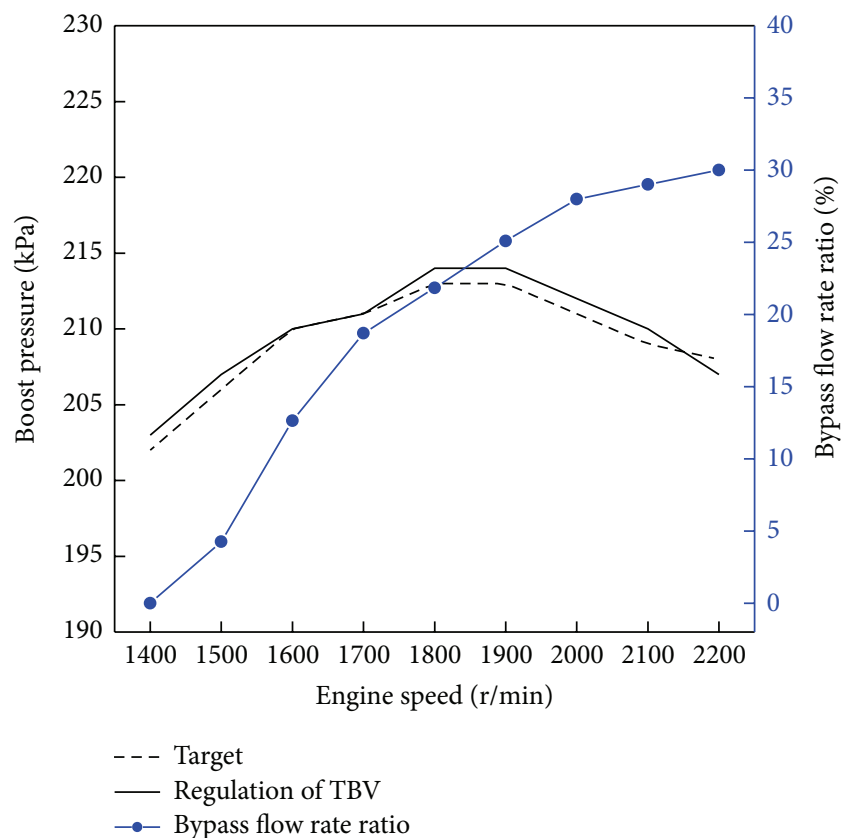

FIGURE 9: Control of the full load boost pressure at different speeds.

total pressure ratio was little changed following changes in engine speed. The pressure ratio of the high pressure stage was still much higher than that of the low pressure stage.

The turbine bypass valve and compressor bypass valve control strategies were determined according to the performance analysis at different speeds and altitudes and are shown in Figures 11 and 12.

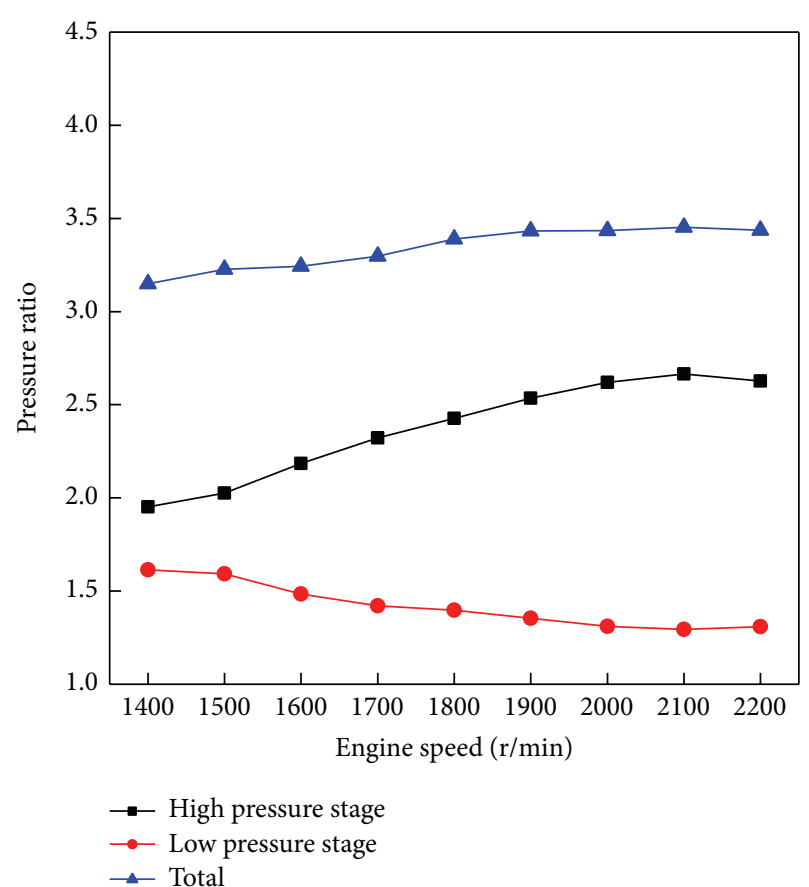

FIGURE 10: Pressure ratios of the two-stage turbocharger at different speeds.

The TBV was, in principle, more important than the CBV. The TBV had three operating modes at different speeds and various altitudes: closed, regulated, and open. The TBV was closed at the altitudes and speeds near the matching point. The opening degree of the TBV increased with increasing engine speed at the same altitude. The opening degree of the TBV decreased with increasing altitude at the same engine speeds.

Here the closed mode was defined as the bypass flow ratio was equal to 0 ; the regulated mode was defined as the bypass flow ratio was between 0.05 and 0.35 ; the open mode was defined as the bypass flow ratio was more than 0.35 . The operating modes of the turbine bypass valve were displayed in Table 2. The opening degree of the TBV increased gradually in the regulated operating mode, and the bypass flow rate ratio was increased from 0.05 to 0.35 . The low pressure turbine provided no turbine power when the bypass flow rate ratio exceeded 0.35 . When the engine operated at lower altitudes and higher speeds, the self-compensation ability of TBP turbocharger was enough to meet the pressure ratio and mass flow rate requirements. Therefore, the TBV could be fully opened to bypass the low pressure turbine, and the RTS system could work as a single-stage turbocharging system.

The CBV only had two operating modes at different speeds and various altitudes: closed or open. The CBV was open only at lower altitudes and higher speeds. Once the TBV was fully open, the CBV together with the TBV enabled complete bypassing of the low pressure turbocharger to avoid flow resistance loss.

The regulation line of the TBV for different loads at the rated speed at $3000 \mathrm{~m}$ is shown in Figure 13. The TBV should 
TABLE 2: Operating modes of the turbine bypass valve.

\begin{tabular}{lccccccccc}
\hline \multirow{2}{*}{ Ambient pressure } & \multicolumn{9}{c}{ Engine speed r/min } \\
& 1400 & 1500 & 1600 & 1700 & 1800 & 1900 & 2000 & 2100 & 2200 \\
\hline $70 \mathrm{kPa}$ & Closed & Closed & Regulated & Regulated & Regulated & Regulated & Regulated & Regulated & Regulated \\
$80 \mathrm{kPa}$ & Closed & Regulated & Regulated & Regulated & Regulated & Regulated & Open & Open & Open \\
$90 \mathrm{kPa}$ & Regulated & Regulated & Regulated & Regulated & Open & Open & Open & Open & Open \\
$100 \mathrm{kPa}$ & Regulated & Regulated & Regulated & Open & Open & Open & Open & Open & Open \\
\hline
\end{tabular}

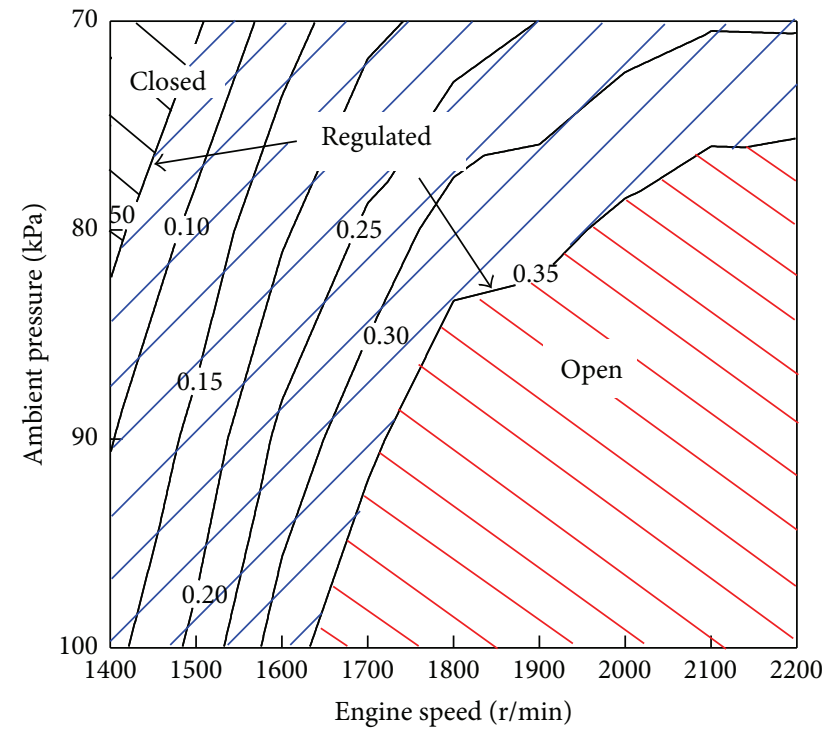

Figure 11: Control strategy of the turbine bypass valve.

be gradually closed to maintain the target boost pressure when the engine loads are decreased. According to Figure 13, when the fuel-injection quantity decreased from $99 \mathrm{mg}$ to $25 \mathrm{mg}$, the bypass flow rate ratio of the TBV decreased from 0.28 to 0 . The fuel-injection quantity gradually decreased with decreasing engine load, leading to lower exhaust energy. Because the self-compensation ability of the turbocharging system is influenced by the exhaust energy, the opening degree of the TBV should be reduced to generate more turbine power.

\section{Power Recovery of Diesel Engine at High Altitude}

As described above, the matched RTS system with the TBC and $\mathrm{CBV}$ control strategies could maintain the target boost pressure at different speeds and various altitudes. The power recovery of the diesel engine at high altitude was then studied.

Overall turbocharger efficiency for the original engine and the RTS system at $3000 \mathrm{~m}$ is shown in Figure 14. When the engine speed was less than $1800 \mathrm{r} / \mathrm{min}$, the efficiencies of the high pressure stage and low pressure stage were higher than that of the original engine. Once the engine speed was increased above $1800 \mathrm{r} / \mathrm{min}$, the efficiency of the low pressure stage was rapidly reduced because of the regulation of the TBV, and the overall efficiency of the RTS system was much

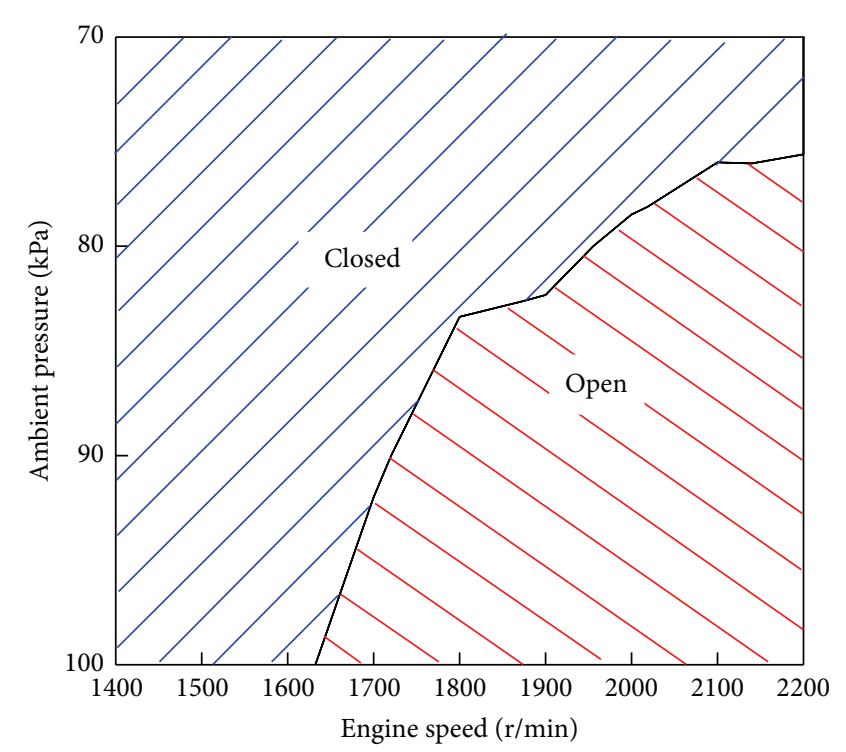

FIGURE 12: Control strategy of the compressor bypass valve.

lower than that of the original engine. The decrease in the overall efficiency of the turbocharging system resulted in the increase of turbine inlet pressure (Figure 15) and affected the power output of the diesel engine.

According to Figure 15, the RTS system provided much higher turbine inlet pressure than the original engine, due to the poor overall efficiency. The difference in turbine inlet pressures between the RTS system and original engine increased with engine speed and reached as high as $43 \mathrm{kPa}$ at $2200 \mathrm{r} / \mathrm{min}$. A higher turbine inlet pressure would deteriorate the pumping process and reduce the brake power of the diesel engine.

The brake powers of the diesel engine at different speeds and various altitudes are presented in Figure 16. With the matched RTS system, the brake power exceeded the target value at full load at speeds of $1400 \mathrm{r} / \mathrm{min}$ and $1500 \mathrm{r} / \mathrm{min}$. The difference between the actual power and the target value increased with increasing engine speed. Therefore, a diesel engine with an RTS system and valve control strategies for recovering the boost pressure could not reach the power recovery targets at speeds above $1500 \mathrm{r} / \mathrm{min}$. A fuel-injection compensation method was investigated to recover the brake power of the diesel engine at different altitudes.

Figure 17 shows the excess air coefficient of the diesel engine based on the recovery of boost pressure at different operating conditions. The maximum value was at high speeds 


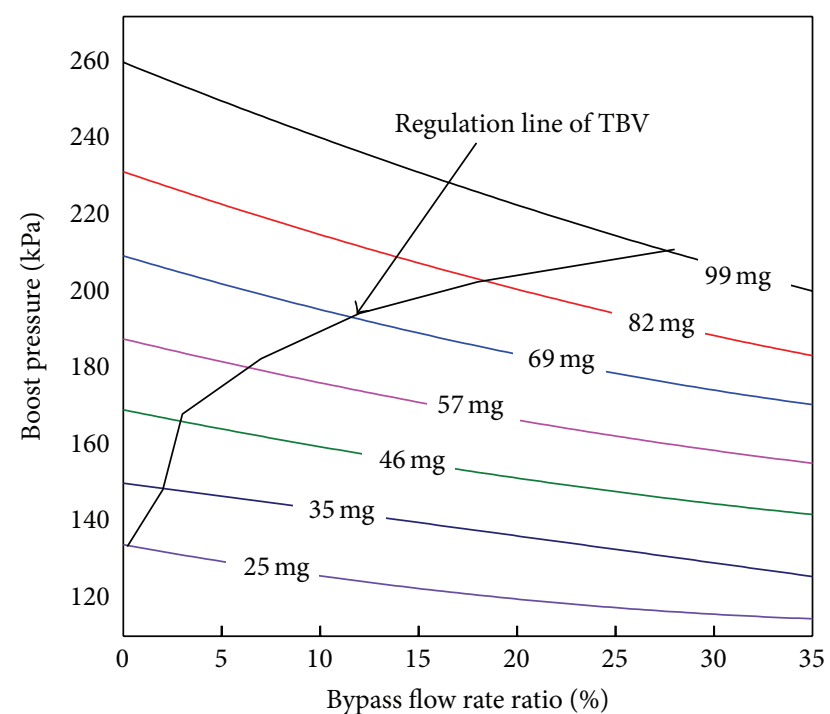

FIGURE 13: Valve control strategy for different loads at the rated speed at $3000 \mathrm{~m}$.

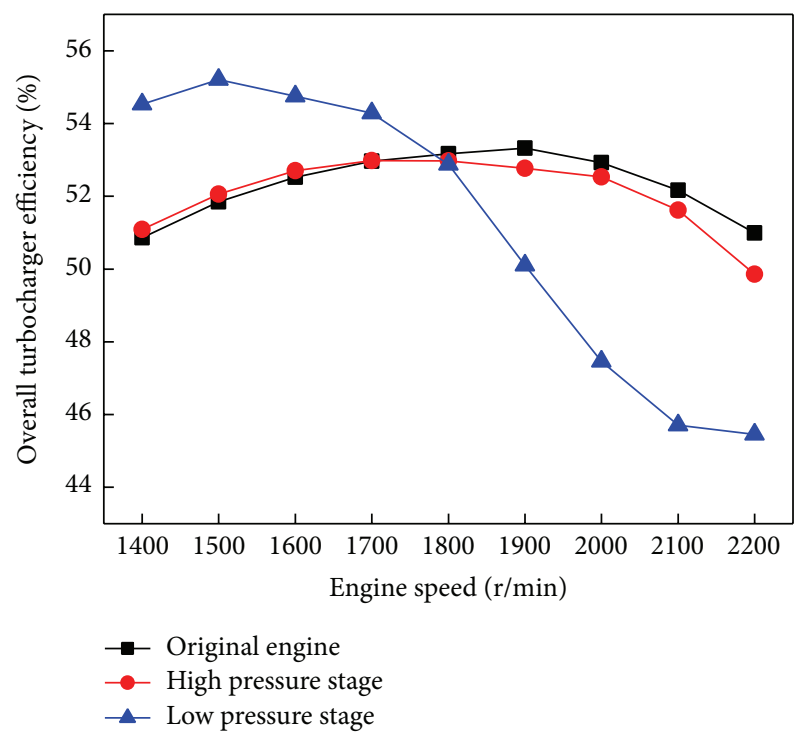

FIGURE 14: Overall turbocharger efficiency for turbocharging systems at $3000 \mathrm{~m}$

and low altitudes, and the minimum value of the excess air coefficient was near the maximum torque speed at altitudes from $0 \mathrm{~m}$ to $3000 \mathrm{~m}$. The excess air coefficient was above 1.8 at different speeds and various altitudes, which is sufficient for a good combustion process. Therefore, the fuel-injection compensation method was feasible for power recovery.

The full load of different speeds and different loads for the rated speed at $3000 \mathrm{~m}$ were the target operating points used to verify the power recovery method. The compensation quantities of fuel-injection are shown in Figures 18 and 19. The fuel-injection quantities at full loads of $1400 \mathrm{r} / \mathrm{min}$ and $1500 \mathrm{r} / \mathrm{min}$ were not compensated because the target was already reached. The compensation quantity of fuel-injection

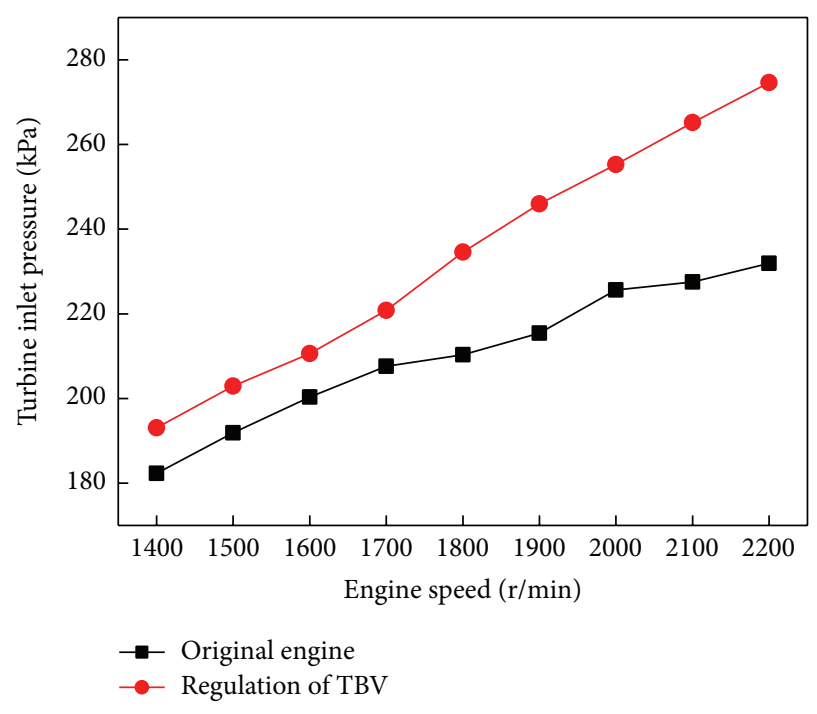

FIGURE 15: The comparison of turbine inlet pressure for different speeds at $3000 \mathrm{~m}$.

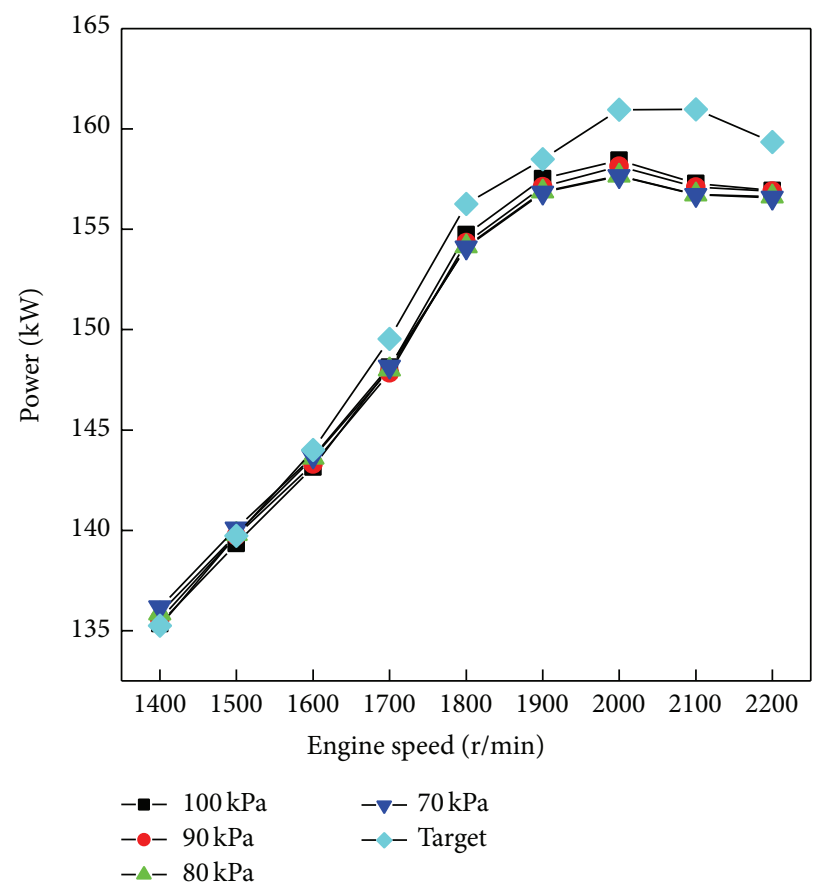

FIGURE 16: The brake power at different speeds and altitudes.

increased with engine speed due to the poor overall turbocharger efficiency (Figure 14). The ratio of compensation quantity to the original engine's cycle fuel-injection quantity was also increased. This could be explained by the increasing difference between the actual power and the target value (Figure 16).

The compensation quantity of fuel-injection also increased with engine load at rated speed, shown in Figure 19. However the compensation quantity was small compared to the cycle fuel-injection quantity of original engine. This shows that the valve control strategy for boost 


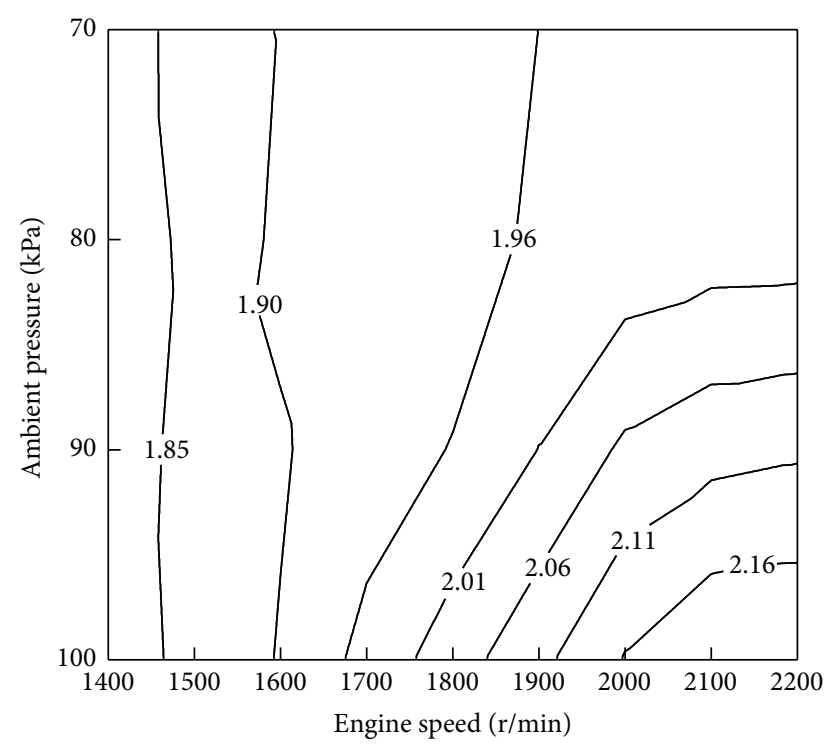

Figure 17: Excess air coefficient of the diesel engine at different operating conditions.

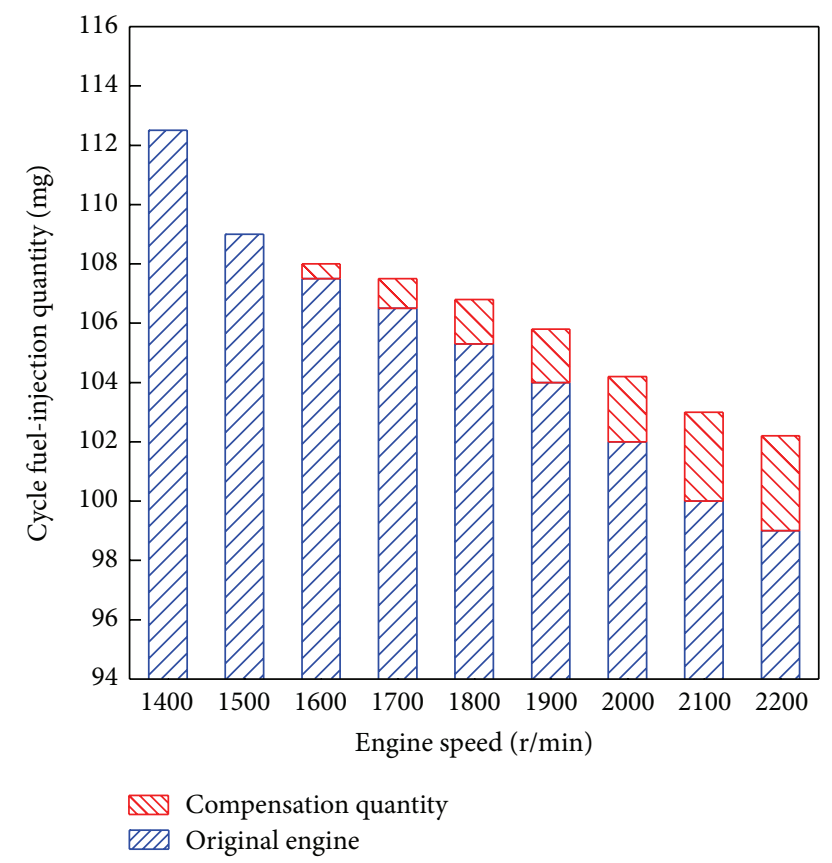

FIGURE 18: Fuel-injection compensation at full load at different speeds.

pressure recovery could almost meet the requirement of power recovery for different loads at the rated speed.

The results of power recovery at the target operating points are shown in Figures 20 and 21. The brake power of the diesel engine exceeded the target value with the fuelinjection compensation method. Therefore, this method of power recovery together with the control strategy for boost pressure recovery improved the dynamic performance at high altitudes.

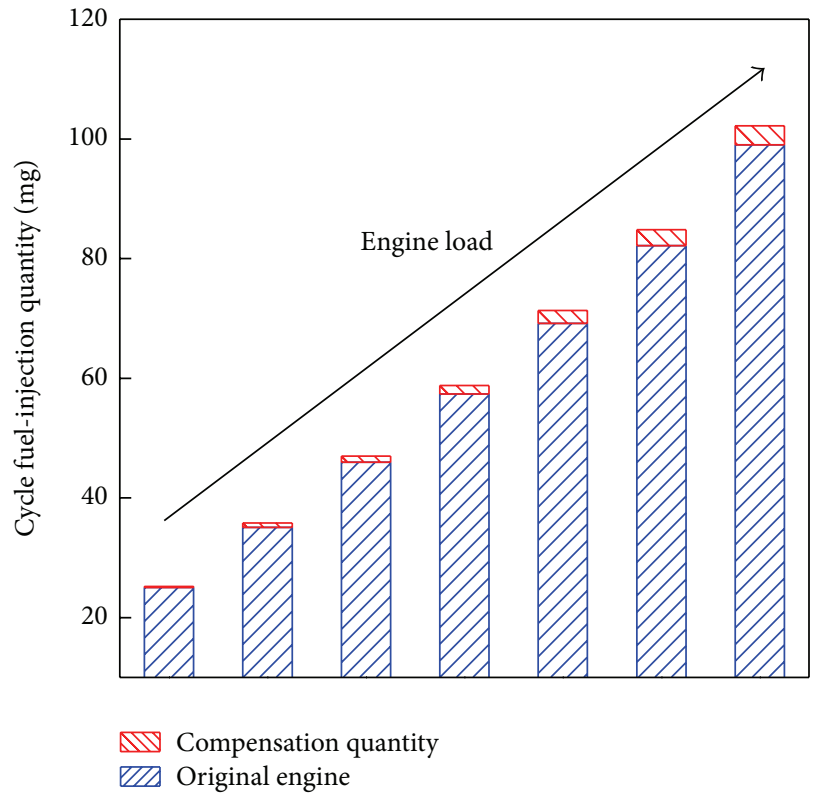

FIGURE 19: Fuel-injection compensation at different loads at rated speed.

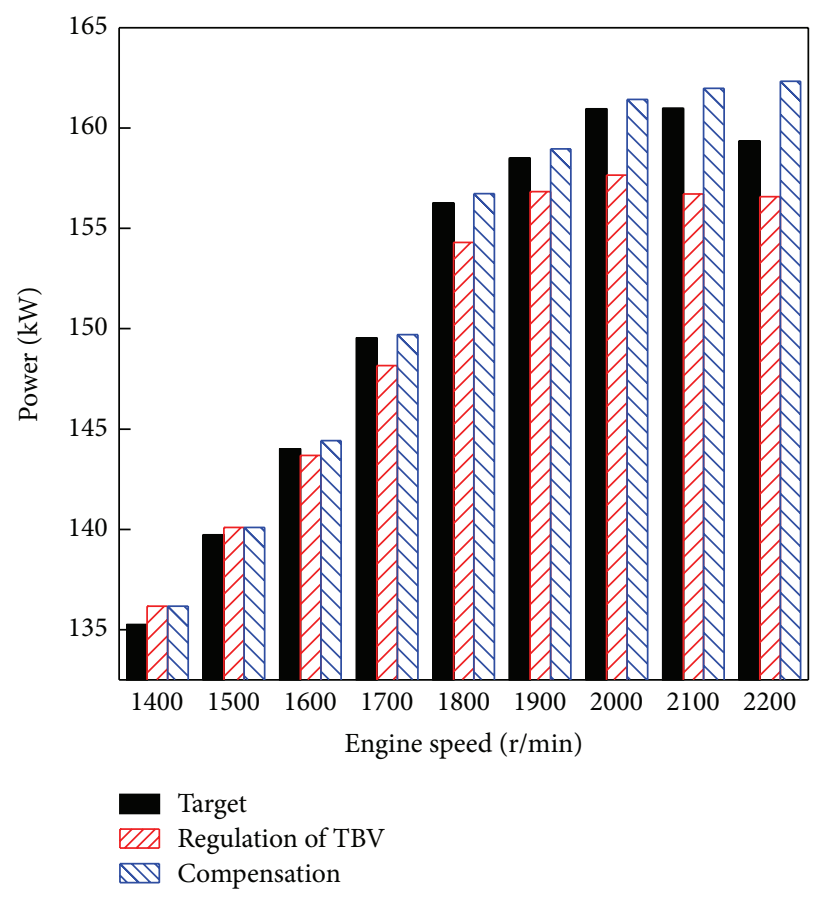

FIGURE 20: Brake powers for different speeds at full load.

Figure 22 shows the operating lines for power recovery in the diesel engine at high altitude. From the compressor maps it was clear that the full load operating line passed through the region of highest efficiency for the high pressure compressor (TBP4 compressor). The pressure ratios of the high pressure turbocharger (TBP4) and low pressure turbocharger (GT4508) are also shown. The speed of the low pressure turbocharger is very low (about $44000 \mathrm{r} / \mathrm{min}$ ) at high 


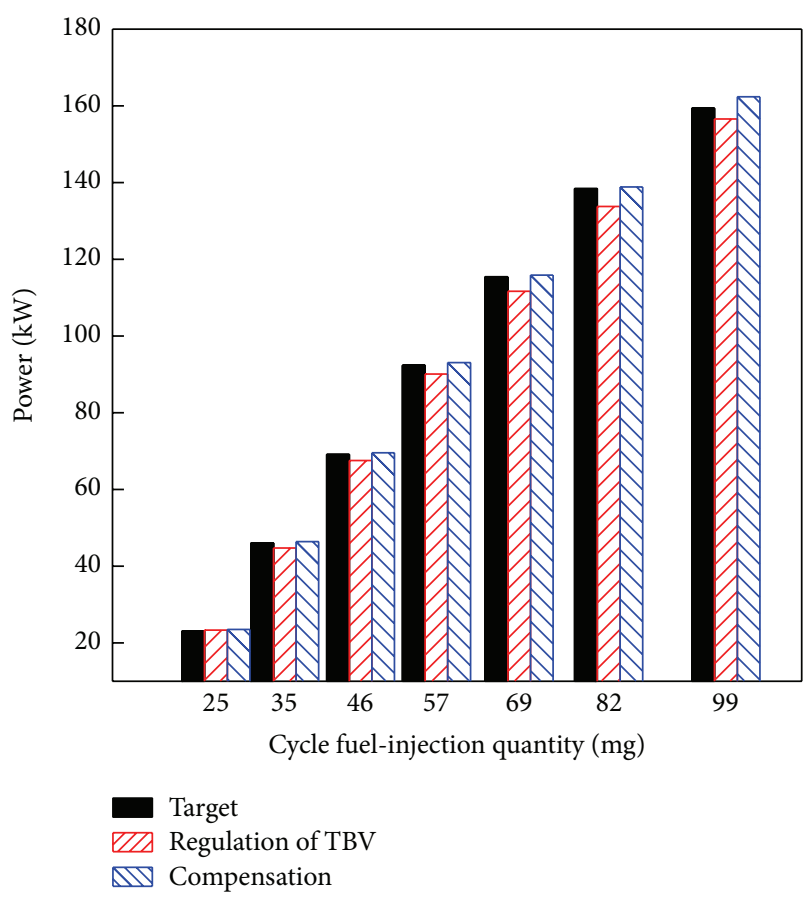

FIGURE 21: Brake powers for different loads at rated speed.

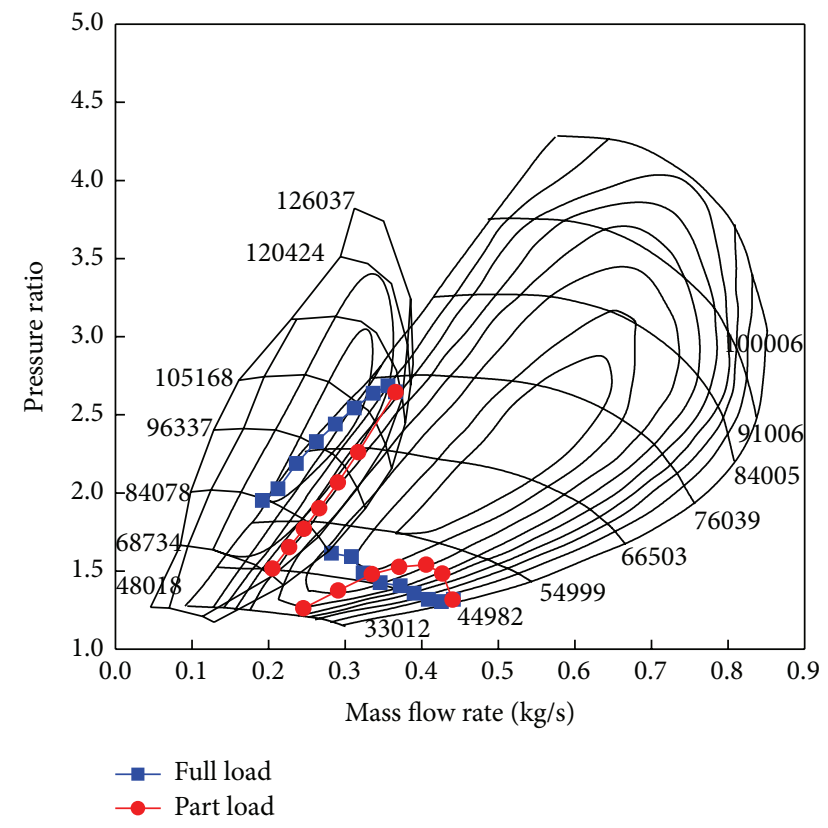

FIGURE 22: The operating lines for power recovery in the diesel engine at $3000 \mathrm{~m}$.

engine speed because of the self-compensation ability of the high pressure turbocharger and the valve control strategy for boost pressure recovery. The low pressure turbocharger always operated to assist the compression of intake air, and the high pressure turbocharger played an important role in the entire compressor process.

\section{Conclusions}

Based on the simulations of power recovery in a diesel engine with a regulated two-stage turbocharging system at different altitudes, several conclusions could be drawn.

(1) The rate of reduction of the boost pressure and engine power was affected by the engine speed. The self-compensation ability changed with engine speed; better self-compensation was achieved with higher engine speeds.

(2) The matched, regulated two-stage turbocharging system was able to recover the boost pressure based on the suitable control of the turbine bypass and compressor bypass valves. The two bypass valves had their own operating modes for different speeds and altitudes.

(3) The boost pressure recovery could not meet the requirement of power recovery over the entire operating range of the diesel engine. The poor overall turbocharger efficiency affected the turbine inlet pressure and decreased the dynamic performance of the diesel engine.

(4) The fuel-injection compensation method together with the valve control strategies for boost pressure recovery could meet the power recovery targets at different altitudes.

\section{Conflict of Interests}

The authors declare that there is no conflict of interests regarding the publication of this paper.

\section{References}

[1] L. Shen, Y. Yang, J. Lei, Y. Bi, W. Yan, and Y. Yang, "Study of performance and emissions of a turbocharged inter-cooling diesel engine at different altitudes," Transactions of CSICE, vol. 24, no. 3, pp. 250-255, 2006.

[2] R. Liu, H. Liu, and D. Qin, "Experimental study on performance of turbocharged diesel engines at high altitude (low air pressure)," Transactions of CSICE, vol. 21, no. 3, pp. 213-216, 2003.

[3] H. Hiereth and P. Prenninger, Charging the Internal Combustion Engine, Springer, Wien, Germany, 2003.

[4] N. C. Baines, Fundamentals of Turbocharging, Concepts NREC, Vermont, Vt, USA, 2005.

[5] Watson, Turbocharging the Internal Combustion Engine, Macmillan Press, London, UK, 1982.

[6] S. Saulnier and S. Guilain, "Computational study of diesel engine downsizing using two-stage turbocharging," SAE Paper 2004-01-0929, 2004.

[7] F. Steinparzer, "The BMW six-cylinder engine with two-stage turbo charging," AutoTechnology, vol. 7, no. 7, pp. 44-47, 2007.

[8] A. Plianos and R. Stobart, "Modeling and control of diesel engines equipped with a two-stage turbo-system," SAE Paper 2008-01-1018, 2008.

[9] N. Gandhi, N. Gokhale, Y. Aghav et al., "Development of two stage turbo -charging for medium duty diesel engine of power generation application," SAE Paper, 2012-28-0007, 2012. 
[10] X. Liu, M. Wei, C. Ma, and X. Shi, "Simulation on one-stage and two-stage turbocharged diesel engines at different altitudes," Transactions of CSICE, vol. 28, no. 5, pp. 447-452, 2010.

[11] X. Shi and W. Li, "Simulation on plateau performance of diesel engine matched with two-stage sequential turbocharging system," Acta Armamentarii, vol. 32, no. 4, pp. 397-402, 2011.

[12] Y. Wang, Y. Li, X. Chen, and B. Li, "Two-stage turbocharging matching of light aero-engine at high altitude," Journal of Aerospace Power, vol. 26, no. 5, pp. 1099-1103, 2011. 

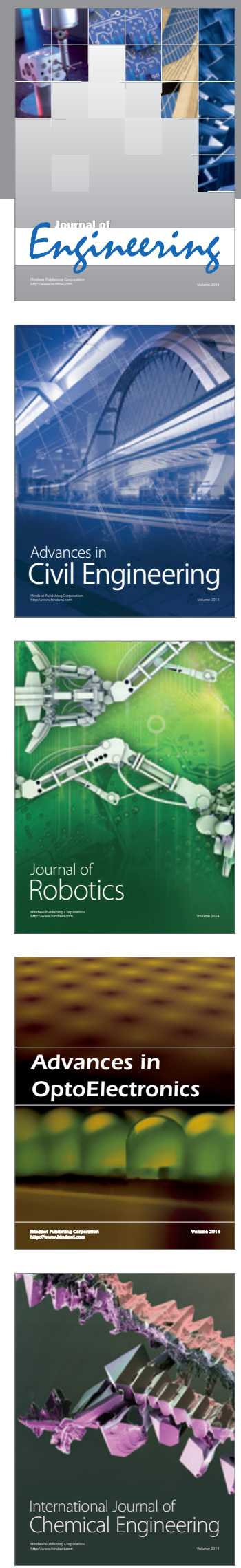

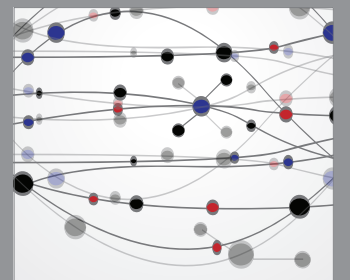

The Scientific World Journal
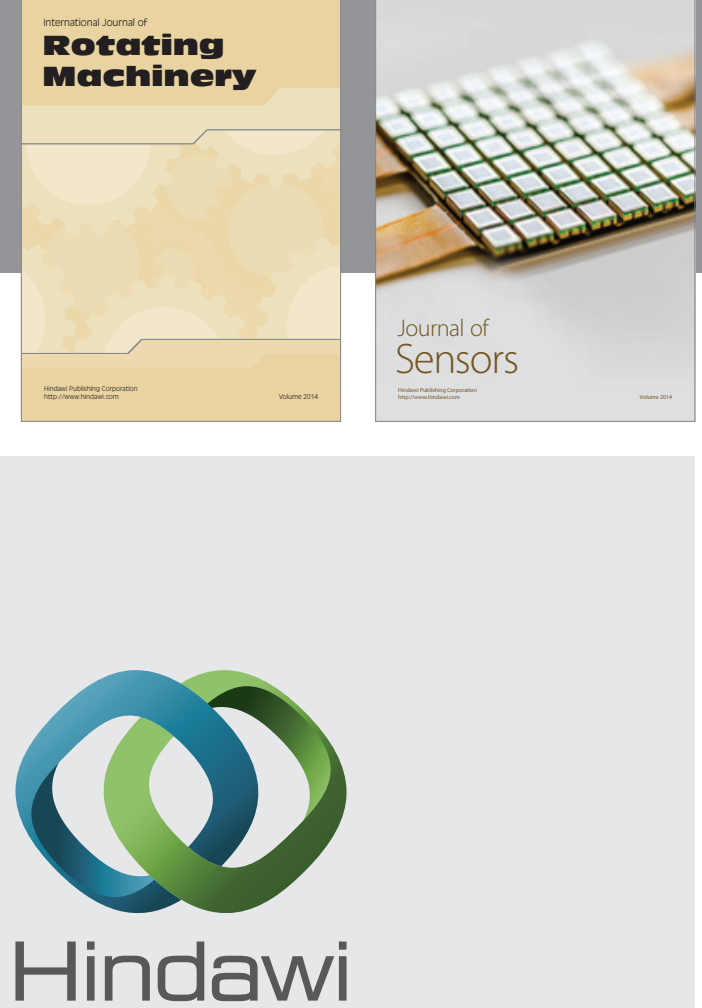

Submit your manuscripts at http://www.hindawi.com
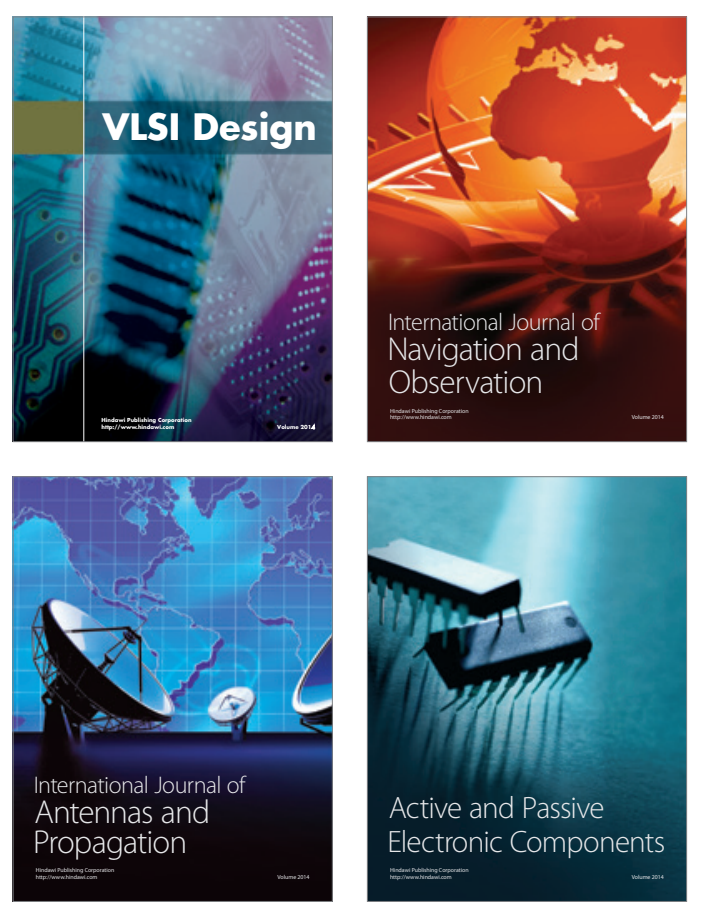
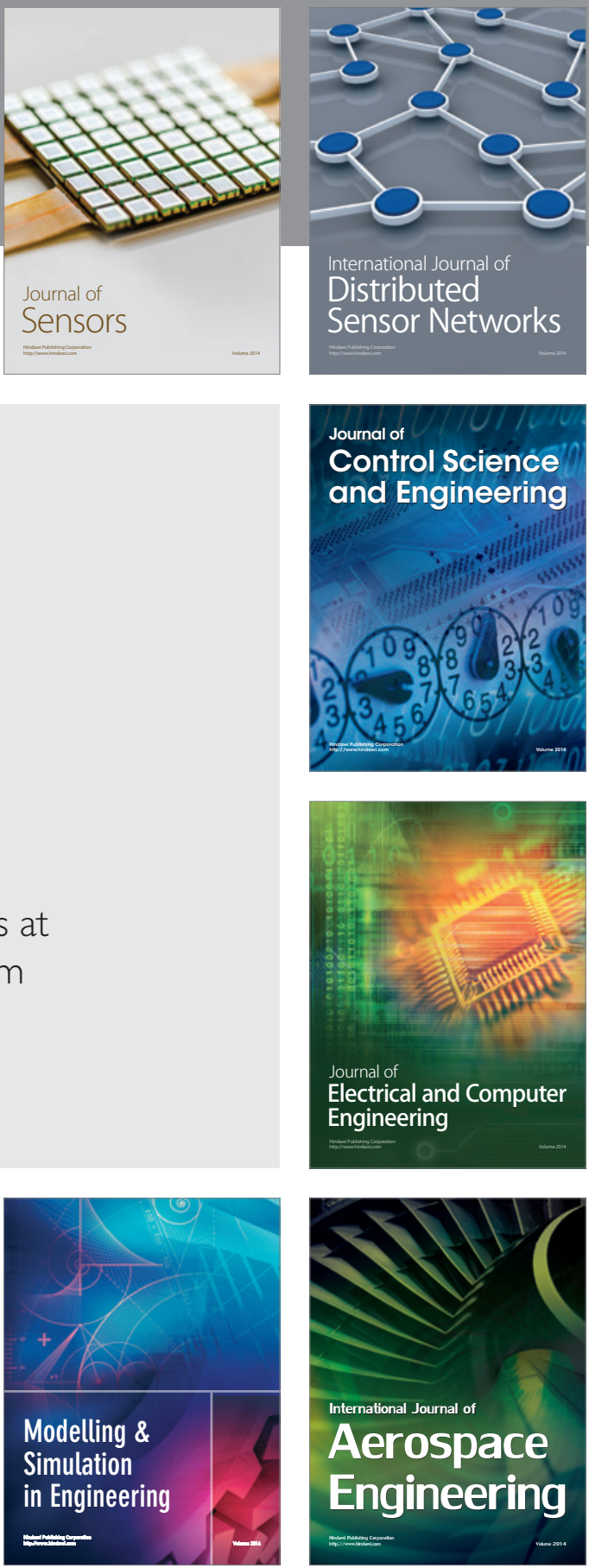

Journal of

Control Science

and Engineering
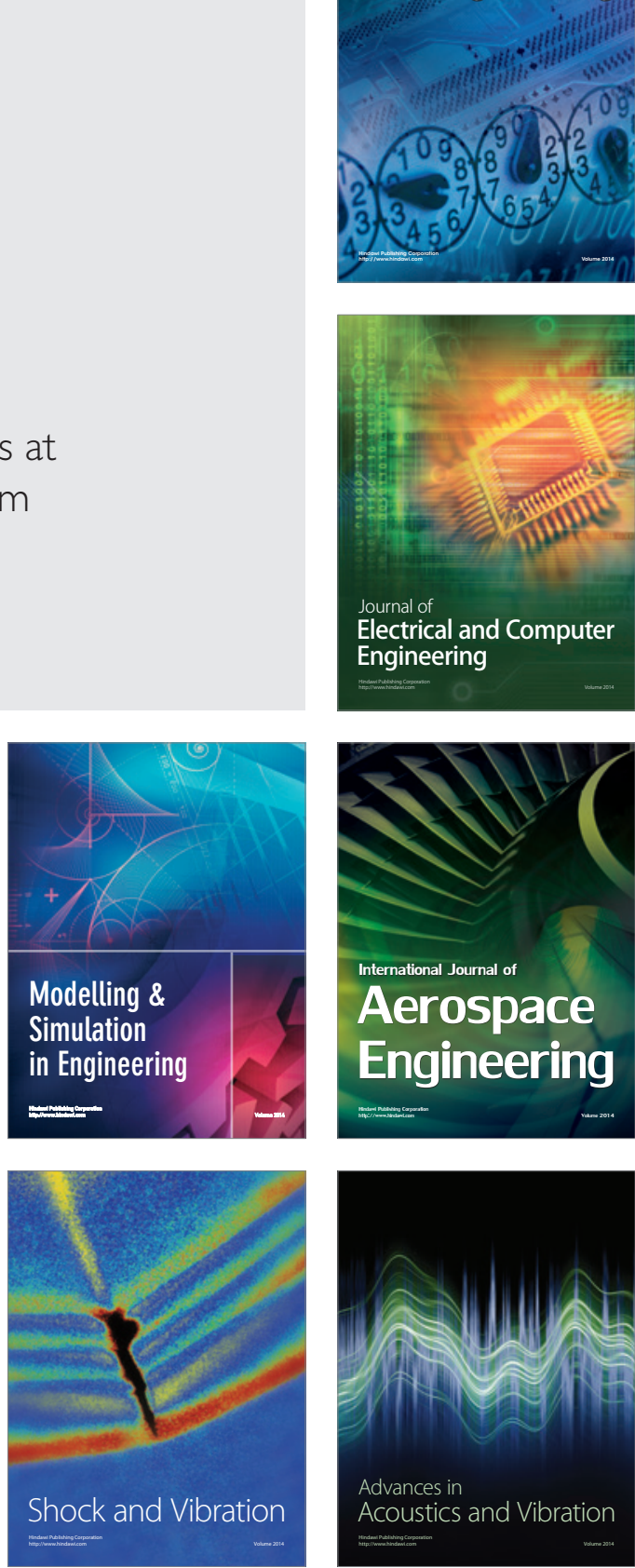